\title{
Response to Treatment of Helicobacter pylori- associated Dyspepsia: Eradication of Helicobacter pylori or Correction of Gastric or Intestinal Dysbiosis?
}

TO THE EDITOR: We have a special interest in the findings reported by Kim et al. ${ }^{1}$ that the symptom response following treatment for Helicobacter pylori in functional dyspepsia (FD) depends on the type of antibiotic used (metronidazole better than clarithromycin), the duration of therapy (10-14 days better than 7 days), and the presence or absence of concomitant irritable bowel syndrome (IBS). The authors speculate that the symptom relief could also be due to correction of accompanying intestinal dysbiosis.

Some years ago, we showed that patients with non-ulcer dyspepsia (now termed FD) had altered colonic motility, irrespective of the subtype (ulcer type-now termed epigastric pain syndrome, or dysmotility type — now termed postprandial distress syndrome). ${ }^{2}$ We suggested that the dysmotility in these patients is a diffuse phenomenon although the presenting symptom may be localized. Recent literature accepts that there is an overlap between FD and IBS. We had also reported then that short courses of metronidazole give symptom relief in IBS. ${ }^{3}$ Thus, the authors' observation that patients with FD respond better to anti-H. pylori treatment regimens incorporating metronidazole and in the presence of IBS, is not surprising.

We recently reported that the gastric microbiota in patients infected with $H$. pylori differs between those with and without $\mathrm{FD},{ }^{4}$ and the intricate networking between $H$. pylori and the concomitant gastric microbiota. ${ }^{5}$ There has been speculation that the relief of symptoms after $H$. pylori treatment could also be due to eradication of coexisting bacteria in the stomach. ${ }^{6}$

The issue is thus more complex than it seems. In FD, does metronidazole provide relief by affecting $H$. pylori, the concomitant gastric microbiota, or the intestinal microbiota? Since intestinal microbiota may have a role in IBS pathogenesis, is relief of FD symptoms partially affected by relief of IBS symptoms, the two con- ditions known to overlap?

Philip Abraham and Verima Pereira

Division of Gastroenterology, P D Hinduja Hospital, Mumbai, India

1. Kim YJ, Chung WC, Kim BW, et al. Is Helicobacter pylori associated functional dyspepsia correlated with dysbiosis? J Neurogastroenterol Motil 2017;23:504-516.

2. Nabar AA, Bhatia SJ, Abraham P, Ravi P, Mistry FP. Total and segmental colonic transit time in non-ulcer dyspepsia. Indian J Gastroenterol 1995;14:131-133.

3. Nayak A, Karnad D, Abraham P, Mistry FP. Metronidazole relieves symptoms in irritable bowel syndrome: the confusion with so-called “chronic amebiasis.". Indian J Gastroenterol 1997;16:137-139.

4. Pereira V, Abraham P, Nallapeta S, Shetty A. Gastric bacterial flora in patients harboring Helicobacter pylori with or without chronic dyspepsia: analysis with matrix-assisted laser desorption ionization time-of-flight mass spectroscopy. BMC Gastroenterol 2018;18:20.

5. Das A, Pereira V, Saxena S, et al. Gastric microbiome of Indian patients with Helicobacter pylori infection, and their interaction networks. Sci Rep 2017;7:15438

6. Holtmann G, Talley NJ. Functional dyspepsia. Curr Opin Gastroenterol 2015;31:492-498.

Financial support: None. Conflicts of interest: None.

Author contributions: Philip Abraham and Verima Pereira have contributed to the intellectual component, drafting, and finalization of the manuscript. 